\title{
Avaliação do Efeito da Energia de Soldagem na Deposição de Aço Inoxidável Superduplex pelo Processo Plasma Pó
}

\author{
Everton Barbosa Nunes ${ }^{1}$, Nathália Escóssio Cavalcante ${ }^{1}$, Alexandre Sousa Barreto ${ }^{1}$, Antônio Ítalo Neves da Silva ${ }^{2}$, \\ Marcelo Ferreira Motta ${ }^{1}$ \\ 1 Departamento de Engenharia Metalúrgica e de Materiais, Universidade Federal do Ceará - UFC, Fortaleza, CE, Brasil. \\ 2 Departamento de Engenharia Mecânica e de Produção, Universidade Federal do Ceará - UFC, Fortaleza, CE, Brasil.
}

Recebido: 03 Mar., 2015

Aceito: 29 Jun., 2015

E-mail: nunesbar@ibest.com.br (EBN)
Esteé um artigo publicado em acesso aberto (Open Access) sob a licença Creative Commons Attribution Non-Commercia que permite uso, distribuiçăo e reproduçăo em qualq'uer meio, sem restriç̄oes desde que sem fins comerciais e que 0 trabalho original seja corretamente citado.
Resumo: O processo plasma pó é um dos mais recentes na aplicação de revestimento, possuindo como principal característica o controle da diluição. A soldagem de revestimento com aços inoxidáveis superduplex é uma interessante opção para a construção e o reparo de equipamentos para aplicações em ambiente de corrosão severa, permitindo alcançar as características desejadas:resistência à corrosão e boas propriedades mecânicas. Logo, este trabalho tem como objetivo avaliar o teor de ferrita no metal de solda e as características mecânicas através de perfis de microdureza em soldagens de revestimentos de dutos de aço C-Mn com deposição de UNS S32760 depositadas pelo processo Plasma Pó. Foram realizadas soldagens em dutos com deposição de AISD, empregando três níveis de energia de soldagem, variando a velocidade ou corrente de soldagem. Posteriormente, foi feita a análise de geometria e quantificação do teor de ferrita no metal de solda e levantamento do perfil de microdureza. A variação da energia de soldagem acarretou mudanças na geometria do cordão de solda, sendo que a alteração da corrente de soldagem proporcionou alterações mais significativas. O aumento da energia acarretou na redução do teor de ferrita do metal de solda. Em relação à microdureza, apenas a condição de maior nível de corrente de soldagem apresentou níveis bastante elevados de microdureza no metal de solda.

Palavras-chave: Plasma; Superduplex; Revestimento.

\section{Evaluation of the Effect of the Heat Input in the Super Stainless Steel Deposition by Powder Plasma Process}

\begin{abstract}
The powder plasma process is one of the latest on weld overlay application and it has as main feature getting the dilution control. The weld overlay with the Super Duplex Stainless Steels is an interesting alternative for the construction and repair of equipment for applications in severe corrosive medium corrosion, allowing reach the desirable characteristics: good resistance corrosion and mechanical properties. Soon, the main objective of the present work is to evaluate the ferrite content in the weld metal and mechanical properties through microhardness profile in weld overlay of C-Mn pipes with UNS S32760 deposition by powder plasma process. Three welding energy levels, varying the speed or welding current, had been carried in the pipes with SDSS deposition. Later, it had carried geometry analysis and quantification of ferrite content in the weld metal and microhardness profile survey. The variation of welding current caused changes in the geometry of weld bead, being the change of welding current provided the most significant changes. Higher levels of heat input resulted in the reduction of the ferrite content of the weld metal. Regarding to the microhardness, just the condition of higher level of welding current high enough levels presented microhardness on weld metal.
\end{abstract}

Key-words: Plasma; Superduplex; Weld overlay.

\section{Introdução}

Na fabricação ou na manutenção dos equipamentos ou componentes, a soldagem é utilizada, sendo de suma importância a utilização de procedimento adequado, de modo a não afetar as propriedades mecânicas e metalúrgicas dos materiais. Nota-se um horizonte em expansão em relação da maior utilização de dutos no Brasil que ainda está defasada em relação a outros países, como a Argentina [1]. Dentro deste cenário, a degradação de superfícies expostas a ambientes agressivos em termos de corrosão, desgaste e/ou temperatura impõem um desafio a engenheiros e pesquisadores visando um aumento da vida útil de componentes/equipamentos, com consequente redução de gastos de manutenção e sucata industrial. 
Devido ao elevado custo para a fabricação de equipamentos maciços constituídos por ligas de alta resistência à corrosão e/ou mecânica, diversos equipamentos na indústria do petróleo são normalmente construídos com materiais menos nobres, como aços C-Mn e baixa liga, e são revestidos por materiais de excelente resistência à corrosão e propriedades mecânicas. A aplicação de revestimento em equipamentos industriais pode ser feita na forma de overlay. Esta última é realizada através da deposição de uma camada de material com características desejáveis em relação às propriedades mecânicas e microestrutura sobre um substrato, sendo um dos métodos de maior versatilidade e com obtenção de bons resultados [2]. O revestimento pode ser aplicado com objetivo de aumento de resistência ao desgaste, resistência à corrosão, resistência à elevadas temperaturas e carregamentos em relação ao metal base [3-5]. No entanto, existem muitos problemas na soldagem de revestimento por utilizar materiais dissimilares, sendo que as falhas acarretam prejuízos de milhões de reais, sendo essencial a seleção adequada de materiais e processo de soldagem, além de ajuste adequado de parâmetros [6]. Na soldagem de revestimento, a interface é a região mais crítica, pois devido à diluição, a composição química do metal de solda perto da interface é diferente, ocorrendo uma certa heterogeneidade, sendo importante não ocorrer redução das propriedades mecânicas e resistência à corrosão. Nas regiões perto da interface podem ocorrer níveis muito elevados de dureza devido à formação de martensita, sendo que a diferença de propriedades físicas entre metal base e metal de solda pode ocorrer presença de trincas nestas regiões, principalmente em condições severas de serviço.

Em geral, a soldagem de revestimento é feita por processos de soldagem, como: MIG/MAG, aspersão térmica, arame tubular, arco submerso (altos níveis de diluição), eletrodo revestido, TIG com alimentação e pelo processo Plasma Transferred Arc (PTA). Em particular, a técnica de deposição por plasma com arco transferido, utilizando material de adição na forma de pó (plasma pó), tem apresentado resultados muitos atrativos para a deposição de superligas [7].

O processo Plasma Pó, em especial, apresenta uma maior eficiência de deposição, bom controle da taxa de diluição, boa homogeneidade, baixa distorção em revestimentos e estruturas mais refinadas, quando comparado aos processos mais tradicionais, contudo, ainda é muito pouco aplicado, necessitando de estudos para explorar a viabilidade de aplicação na indústria do petróleo, resultando principalmente na redução dos custos e da preservação do meio ambiente [8]. A seleção da liga a ser depositada depende de diversos fatores, como: temperatura, resistência ao desgaste, resistência ao meio corrosivo, características do metal base, relação custo/benefício do componente a ser revestido, custo de processamento, dentre outros [9]. Dentre os materiais existentes comercialmente que possuem excelente combinação entre resistência à corrosão e propriedades mecânicas destacam-se os aços inoxidáveis duplex (AID) e superduplex (AISD) [10].

A utilização de AID/AISD tem crescido, principalmente, apesar da sua produção ser menor em relação aos aços inoxidáveis mais tradicionais. Estes materiais possuem em sua microestrutura original as fases ferrita e austenita, de modo a aliar boas propriedades mecânicas e elevada resistência à corrosão. Esta combinação de propriedades tem popularizado o seu uso em ambientes altamente agressivos [11]. Em algumas situações, AID/AISD podem apresentar melhor resistência à corrosão que ligas de níquel, como por exemplo, quando imersos em solução contendo $12 \% \mathrm{NaCl}, \mathrm{pH} 14$ até temperaturas de 200 C, sendo importante o estudo mais aprofundado destes materiais. Uma das primeiras utilizações de grande escala de um AID foi na fabricação de um condensador que operou de modo satisfatória durante 12 anos, enquanto o mesmo equipamento com titânio e liga de níquel durou respectivamente, 5 e 8 anos, além da boa resistência mecânica. O custo para a utilização do AID foi de US $\$ 300.000,00$, enquanto para a liga de níquel foi de US $\$ 1.000 .000,00$ [12]. Existem poucos trabalhos de soldagem dissimilar investigando a deposição de AID/AISD em materiais menos nobres, porém já são obtidos bons resultados em relação às propriedades mecânicas e resistência à corrosão [13,14]. Atualmente, é comum a deposição de AID/AISD em tubos já cladeados com aço inoxidável austenítico devido à possível elevada diluição que iria alterar as características do metal de solda, principalmente perto da zona de ligação, se ocorresse deposição direta de AID/AISD sobre o substrato [15,16]. Sendo assim, torna-se relevante na soldagem overlay, o controle adequado da diluição e balanço de fases, nas soldagens de revestimento com AID/AISD.

Uma energia de soldagem elevada tende a produzir uma velocidade de resfriamento menor do revestimento, dependendo da espessura do tubo. Como consequência, promove a precipitação de austenita, balanceando em parte a microestrutura. Da mesma maneira, pode favorecer a precipitação de fases intermetálicas e o crescimento de grão. Na situação contrária, uma energia de soldagem baixa leva a uma velocidade de resfriamento elevada. 
Avaliação do Efeito da Energia de Soldagem na Deposição de Aço Inoxidável Superduplex pelo Processo Plasma Pó

Assim, a precipitação de austenita é dificultada, gerando uma fração elevada de ferrita, o que pela sua vez acarreta a precipitação de uma grande quantidade de nitretos de cromo no interior da ferrita. Em ambos os casos têm-se como resultado uma severa diminuição na tenacidade e na resistência à corrosão do material [11]. Desta forma, é primordial o controle do balanço de fases, que é de difícil controle nas soldagens multipasse.

As principais preocupações na soldagem dos AISD são o adequado balanço de ferrita e austenita no metal de solda e a prevenção/redução de precipitação de fases deletérias. A seleção adequada dos parâmetros de soldagem é primordial, além da adição de elementos austenitizantes no metal de adição, controle da diluição ou introdução de nitrogênio na poça de fusão pelo gás de proteção.

A carência de informação a respeito do comportamento de revestimentos depositados com AID/AISD, utilizando processo Plasma Pó é um grande fator motivacional para a realização desta pesquisa, que pretende expandir conhecimentos técnicos, operacionais e metalúrgicos das soldagens com estes materiais utilizando o processo Plasma pó. Logo, este trabalho tem como objetivo analisar a influência da energia de soldagem (variando a corrente ou velocidade de soldagem) em relação às características geométricas, teor de ferrita no metal de solda e perfil de microdureza em soldagens de revestimentos internos de dutos de aço C-Mn com deposição de aços inoxidáveis duplex (UNS S32760) depositadas pelo processo Plasma Pó. Desta forma, a contribuição deste trabalho é de trazer subsídios que se possa verificar a viabilidade de revestimentos com deposição deste materiais nobres, contribuindo para novos campos de aplicação, de modo a poder expandir novos estudos na área.

\section{Materiais e Métodos}

O material a ser aplicado neste trabalho como metal base é o tubo de aço: API $5 \mathrm{~L}$ Grau B com diâmetro nominal de 5 " e espessura de parede de $12,7 \mathrm{~mm}$. Este material é muito utilizado nos sistemas de transporte de gás natural e petróleo [17,18]. O material de adição utilizado foi fornecido com classificação Micro Melt 100, compatível com o UNS S32760, conhecido também como ZERON 100 (nome comercial). Na Tabela 1 são mostradas as composições químicas do metal base e do metal de adição. No pó, a adição de tungstênio tem papel similar ao molibdênio na cinética de repassivação e a adição de cobre aumenta a resistência à corrosão em ambientes ácidos não oxidantes [19].

Tabela 1. Composição química do substrato e metal de adição em forma de pó (\% massa).

\begin{tabular}{lcccccccccccc}
\hline \multicolumn{1}{c}{ Material } & $\mathbf{C}$ & $\mathbf{S i}$ & $\mathbf{M n}$ & $\mathbf{C r}$ & $\mathbf{N i}$ & $\mathbf{M o}$ & $\mathbf{C u}$ & $\mathbf{P}$ & $\mathbf{S}$ & $\mathbf{W}$ & $\mathbf{N}$ & $\mathbf{F e}$ \\
API 5L Gr.B & 0,19 & 0,24 & 0,7 & - & - & - & - & 0,018 & 0,018 & - & - & Bal. \\
AISD UNS S32760 & 0,024 & 0,49 & 0,58 & 25,7 & 6,75 & 3,49 & 0,77 & 0,02 & 0,001 & 0,61 & 0,29 & Bal. \\
\hline
\end{tabular}

Na soldagem dos tubos foi utilizado um suporte que realiza o movimento de rotação do tubo, de modo que a tocha fica parada com a soldagem sendo realizada na posição plana (Figura 1). O eletrodo utilizado foi o de tungstênio com adição de óxido de tório (ângulo de ponta de 20 graus), com diâmetro de 4,0 mm e as soldagens realizadas com Corrente Constante com Eletrodo Negativo (CCEN). O argônio comercialmente puro foi utilizado para os três tipos de gases (proteção, plasma e arraste) do processo Plasma Pó [20]. Na Figura 1 são mostrados os equipamentos utilizados no Plasma Pó.

Em relação à tocha de soldagem, o tipo de injeção de pó é externa, o bocal constritor cônico possui ângulo de saída de 80 graus com quatro orifícios de diâmetro de 1,2 mm. Foram depositados 4 cordões simples ao longo da circunferência do tubo, utilizando faixas de corrente e velocidade de soldagem que proporcionassem boas condições operacionais. Foi utilizado um sistema de aquisição de dados de sinais de corrente e tensão operando com frequência de $9600 \mathrm{~Hz}$.

Foram utilizados como parâmetros fixos: vazão de gás plasma - $3 \mathrm{l} / \mathrm{min}$; vazão de gás de arraste $-4 \mathrm{l} / \mathrm{min}$; vazão de gás de proteção - $15 \mathrm{l} / \mathrm{min}$; DBP - $12 \mathrm{~mm}$; recuo do eletrodo $-1 \mathrm{~mm}$; taxa de alimentação do pó - $22 \mathrm{~g} / \mathrm{min}$. Vale salientar que foram realizadas análises preliminares a respeito das faixas de parâmetros operacionais adequadas em relação às características geométricas e acabamento superficial. Na Figura 2 é mostrada a soldagem realizada pelo processo Plasma Pó. Este trabalho visa um estudo posterior de soldagem de revestimento, sendo importante a obtenção de características geométricas adequadas. 

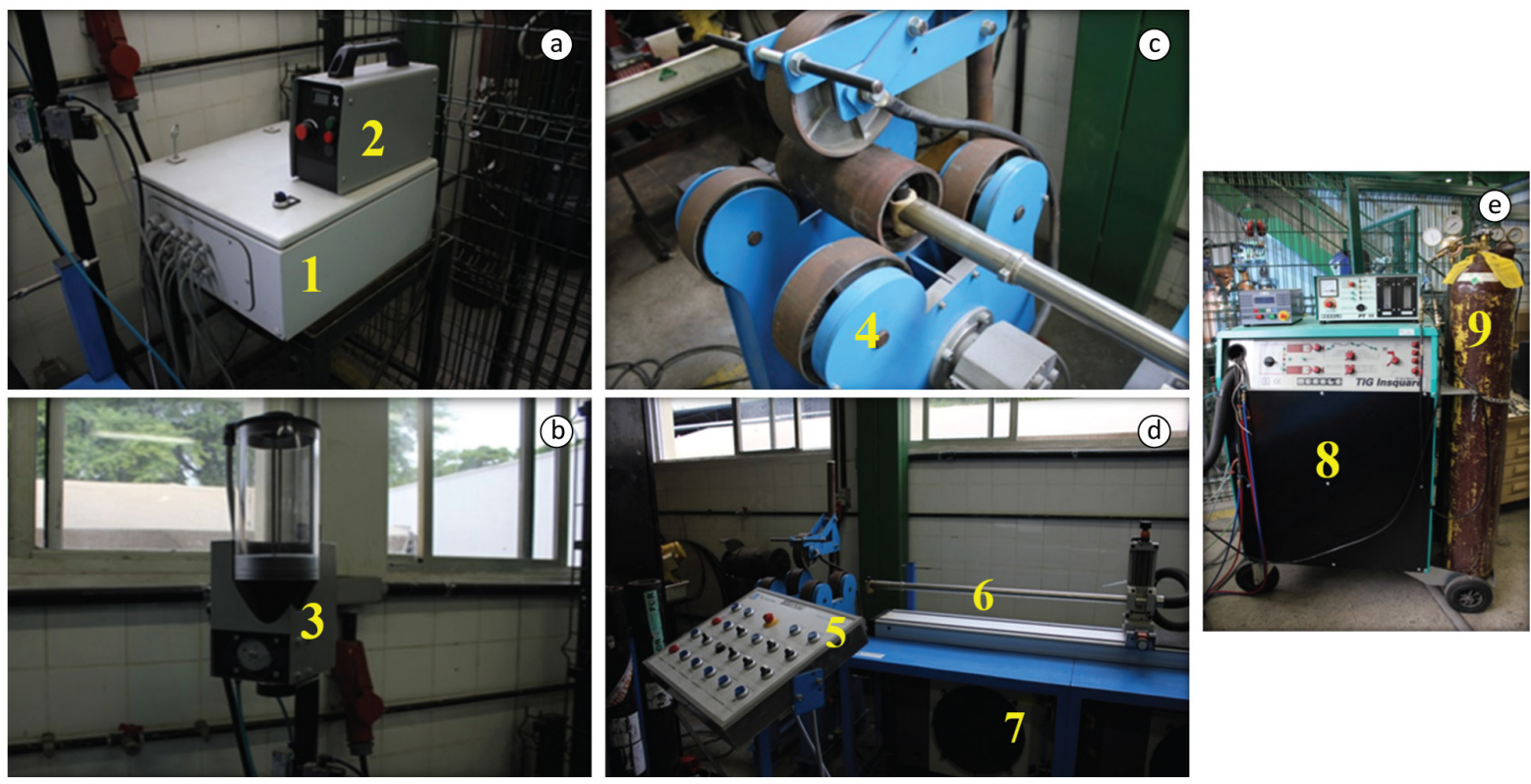

Figura 1. Equipamentos utilizados no Plasma Pó. (a) Unidade de potência (1) e controlador da taxa de alimentação do pó (2); (b) Alimentador de pó (3); (c) Suporte do tubo (4); (d) Unidade de controle (5), tocha (6) e chillers (7); (e) Fonte de soldagem (8) e gases (9).

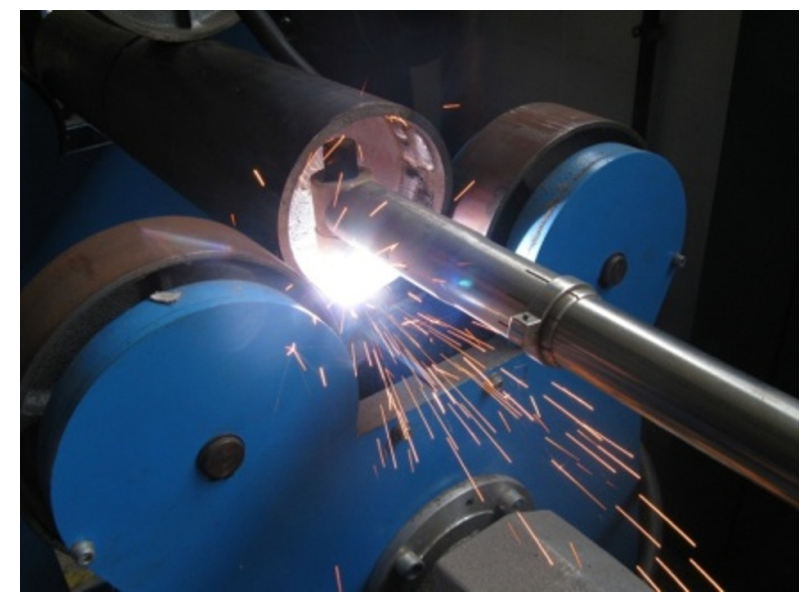

Figura 2. Soldagem realizada pelo processo Plasma Pó.

Na Tabela 2 são mostrados os parâmetros de soldagem, de modo a variar a energia de soldagem pela alteração da corrente ou pela velocidade de soldagem para verificar a influência destes parâmetros nas características geométricas, microdureza e teor de ferrita no metal de solda. $\mathrm{O}$ "tipo I" representa a variação da energia pela alteração da corrente de soldagem $(75,100$ e 150 A), mantendo a velocidade de soldagem constante. Em contrapartida, a designação "tipo V" estar relacionada com a variação do mesmo nível de energia pela alteração da velocidade de soldagem $(6,9$ e $12 \mathrm{~cm} / \mathrm{min})$ que corresponde à velocidade linear do tubo. Vale salientar que nesta pesquisa o tubo que realiza o movimento de rotação e a tocha fica estática. Estes parâmetros foram utilizados devido a um estudo prévio, de modo a obter cordões com baixo nível de diluição e a utilização de velocidades de soldagem mais elevadas. 
Avaliação do Efeito da Energia de Soldagem na Deposição de Aço Inoxidável Superduplex pelo Processo Plasma Pó

Tabela 2. Parâmetros de soldagem.

\begin{tabular}{ccccc}
\hline Ensaio & $\begin{array}{c}\text { Velocidade } \\
(\mathbf{c m} / \mathbf{m i n})\end{array}$ & $\begin{array}{c}\text { Corrente } \\
(\mathbf{A})\end{array}$ & $\begin{array}{c}\text { Energia } \\
(\mathbf{k J} / \mathbf{c m})\end{array}$ & $\begin{array}{c}\text { Tensão } \\
\mathbf{( V )}\end{array}$ \\
01 & 9 & 75 & 12 & 23,5 \\
02 & 9 & 100 & 16 & 23,6 \\
03 & 9 & 150 & 25,7 & 25,3 \\
04 & 6 & 100 & 24,3 & 23,7 \\
05 & 12 & 100 & 12,2 & 24,1 \\
\hline
\end{tabular}

As amostras foram avaliadas em relação ao acabamento superficial e presença de pós não fundidos ao longo do cordão de solda. Em cada corpo de prova foi depositado um cordão de solda com comprimento total de $180 \mathrm{~mm}$. Posteriormente, as amostras foram cortadas na direção transversal com lixamento até 1500 mesh e ataque realizado com Nital 5\% durante 15 s para análise macrográfica. Para a análise macrográfica e obtenção das características geométricas ( 3 medições) foram cortadas duas seções de corpo de prova, no início e fim, com $10 \mathrm{~mm}$ de extensão cada, e descartando-se $15 \mathrm{~mm}$ do início e ao final de cada cordão de solda. A avaliação da influência da corrente e velocidade de soldagem foi realizada pela aplicação do software Statistica, utilizando a análise de variância. A Figura 3 ilustra uma representação esquemática de um cordão de solda seccionado transversalmente, de modo a visualizar com maior clareza o perfil do cordão depositado e as características geométricas analisadas.

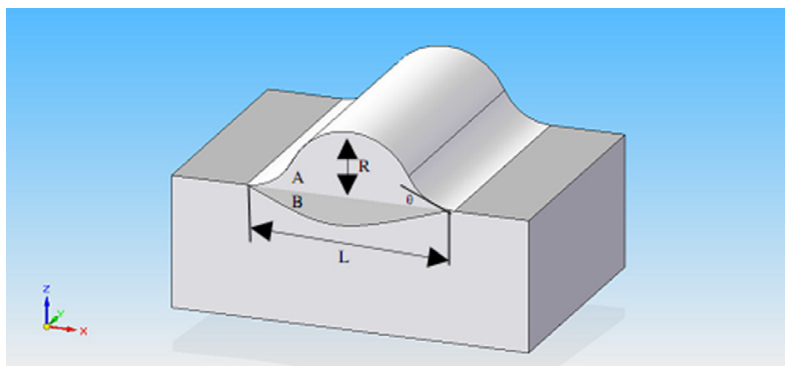

Figura 3. Desenho esquemático da geometria do cordão de solda. $R$ - reforço; L-largura; $\theta$-ângulo de molhamento.

A diluição (D) foi determinada através da análise transversal do cordão de solda, segundo a Equação 1, onde $A_{\text {Adic }}$ é a área adicionada pela deposição da solda e $A_{\text {Dil }}$ é a área do metal de base que fundiu e passou a compor a zona fundida total.

$$
D(\%)=(B / A+B) \times 100
$$

Foram realizadas quantificações do teor de ferrita no metal de solda utilizando o ferritoscópio FISCHER M-30P com 30 medições para cada seção transversal do cordão de solda. Também foram realizados perfis de microdureza vertical, sendo que foi realizada a varredura desde o metal de solda até o metal base, de modo a avaliar a diferença de microdureza do metal de solda em relação ao metal base e possíveis regiões de elevada dureza, principalmente na interface metal de solda/substrato. Foi utilizada uma carga de $100 \mathrm{~g}$ com tempo de aplicação da carga de $15 \mathrm{~s}$ com espaçamento entre impressões de 0,2 $\mathrm{mm}$.

Foi selecionada a melhor faixa operacional, de modo a obter menor diluição, bom molhamento, bom acabamento superficial, níveis de microdureza e teor de ferrita do metal de solda aceitáveis. 


\section{Resultados e Discussão}

A caracterização da morfologia do pó de AISD UNS S32760 foi realizada por Microscopia Eletrônica de Varredura (MEV), como mostrada na Figura 4. São observadas partículas em sua maioria de forma esférica (tamanho de partícula na faixa de 45-105 $\mu \mathrm{m}$ ) que são benéficas por possuírem maior capacidade de arraste, maior eficiência de fusão e menor retenção de umidade [21]. Esta morfologia é característica de pós obtidos por atomização a gás.
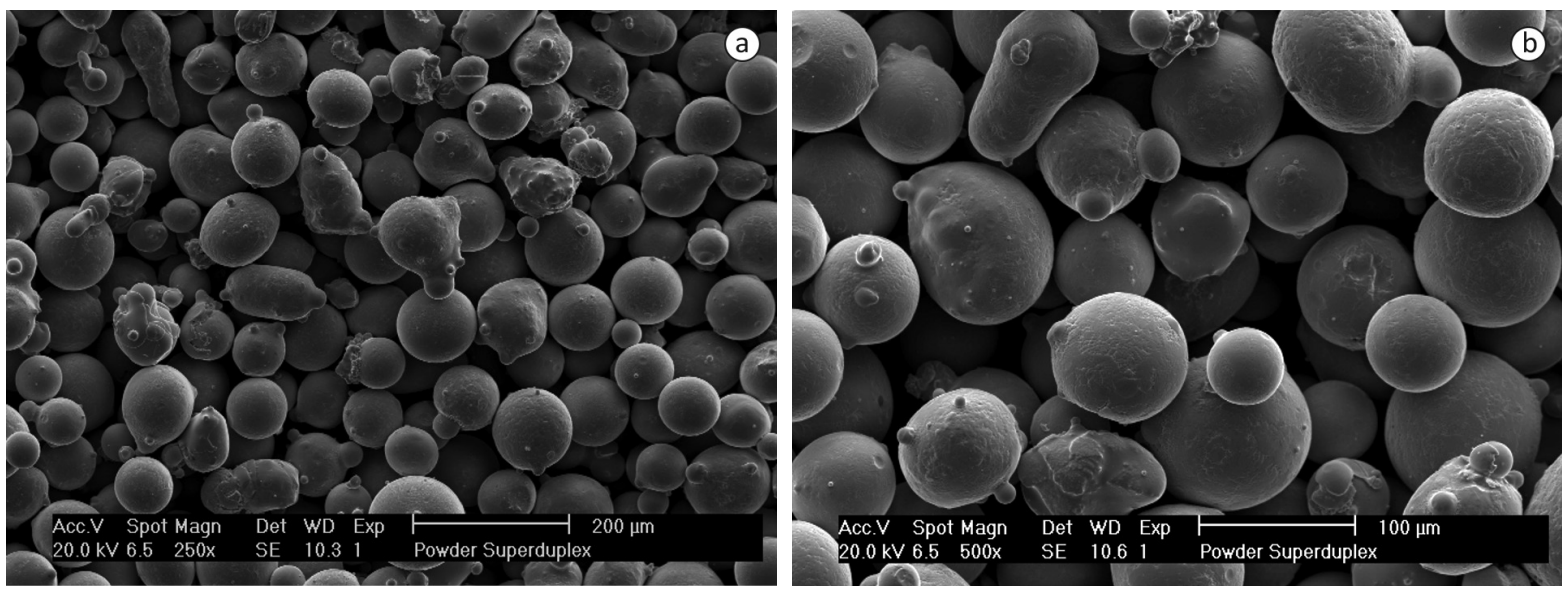

Figura 4. Morfologia dos pós de AISD feito por Microscopia Eletrônica de Varredura (MEV). (a) aumento de 250X; (b) Liga AISD - aumento de 500X.

Na Figura 5 é mostrado o padrão de raios-X para o pó de AISD UNS S32760 para caracterizar o material como recebido. No difratograma existem somente picos de ferrita e austenita, porém com diferentes intensidades, ou alturas de pico. Os picos da ferrita estão localizados nos ângulos: $44,48^{\circ} ; 64,7^{\circ} ; 81,9^{\circ}$. Os picos da austenita estão localizados nos ângulos: $43,14^{\circ} ; 50,22^{\circ} ; 73,88^{\circ}$ e $89,52^{\circ}$. São observadas diferenças de intensidades dos picos de ferrita e austenita em função da orientação das fases, sendo que os picos de ferrita estão mais intensos. A análise quantitativa foi realizada empregando o método de Rietveld, que tem como principal característica o ajuste dos parâmetros estruturais de um modelo da estrutura e parâmetros instrumentais. O refinamento foi feito como o software DBWSTools. As diferenças de intensidade dos picos determinam diferentes balanços de ferrita e austenita, de modo que o teor de ferrita obtido foi de $81,73 \%$ devido à alta velocidade de resfriamento obtido pelo processo de atomização.

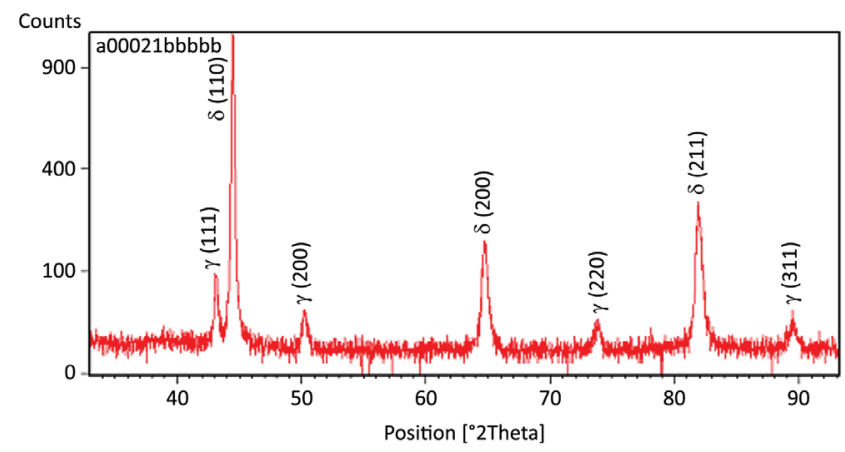

Figura 5. Espectro da difração de raios-X do pó AISD UNS S32760. 
Avaliação do Efeito da Energia de Soldagem na Deposição de Aço Inoxidável Superduplex pelo Processo Plasma Pó

Um dos critérios de avaliação desta etapa foi o acabamento superficial dos corpos de prova soldados. Os cordões de solda apresentaram boa homogeneidade e pouca quantidade de pó não fundido em cima do metal de solda e nas laterais do cordão. Foi verificado que todos os cordões de solda apresentaram pós não fundidos em maior abundância no final do cordão de solda em relação ao início do cordão. Este comportamento foi observado devido ao delay entre a interrupção do arco principal e da injeção de pó, sendo que quando o arco é interrompido, a tocha continua injetado pó em relação ao substrato. Outro aspecto que deve ser analisado é o ângulo de convergência elevado do bico constritor que é de $80^{\circ}$ em relação à DBP utilizada que foi de $12 \mathrm{~mm}$, sendo maior em relação aos bicos mais utilizados comercialmente (30 e 60 graus). Devido à esta característica, no arco voltaico é muito reduzido o tempo de contato, sendo portanto necessário absorver mais calor da massa líquida para a fusão completa do pó injetado. Devido à esta característica, maior a exigência do controle da corrente e da velocidade de soldagem.

Outra observação realizada foi que o aumento da energia de soldagem pela alteração da corrente de soldagem proporcionou redução significativa dos pós não fundidos (Figura 6). Ribeiro [22] também verificou em seu trabalho que valores de corrente muito baixas, o calor gerado não é suficiente para fundir todo o pó injetado, ocorrendo partículas não fundidas, sendo que foi observado que quando se trabalhou com correntes elevadas, os pós que possuem tamanho de partícula pequeno foram volatizadas no arco plasma e o rendimento de deposição diminui. O autor, para eliminar as partículas não fundidas dos depósitos preliminares procurou-se incrementar a energia de soldagem através do aumento da corrente de 100A para 160 A, porém Ribeiro, verificou que o aumento da energia não foi o suficiente para eliminar as partículas não fundidas, mas reduziu em média aproximadamente $65 \%$ a sua quantidade, porém produziu diluição excessiva. Em outro trabalho verificaram níveis baixos de corrente (abaixo de 150 A) proporcionaram incompleta fusão do pó e falta de penetração na deposição de aço inoxidável 316L em aço carbono [23]. Desta forma, os resultados obtidos nesta pesquisa corroboram com resultados já obtidos na lieratura, sendo que o nível de pós não fundidos foi relativamente pequeno em comparação com Ribeiro que realizou soldagens com taxa de alimentação de pó bem menor, em torno de $10 \mathrm{~g} / \mathrm{min}$.

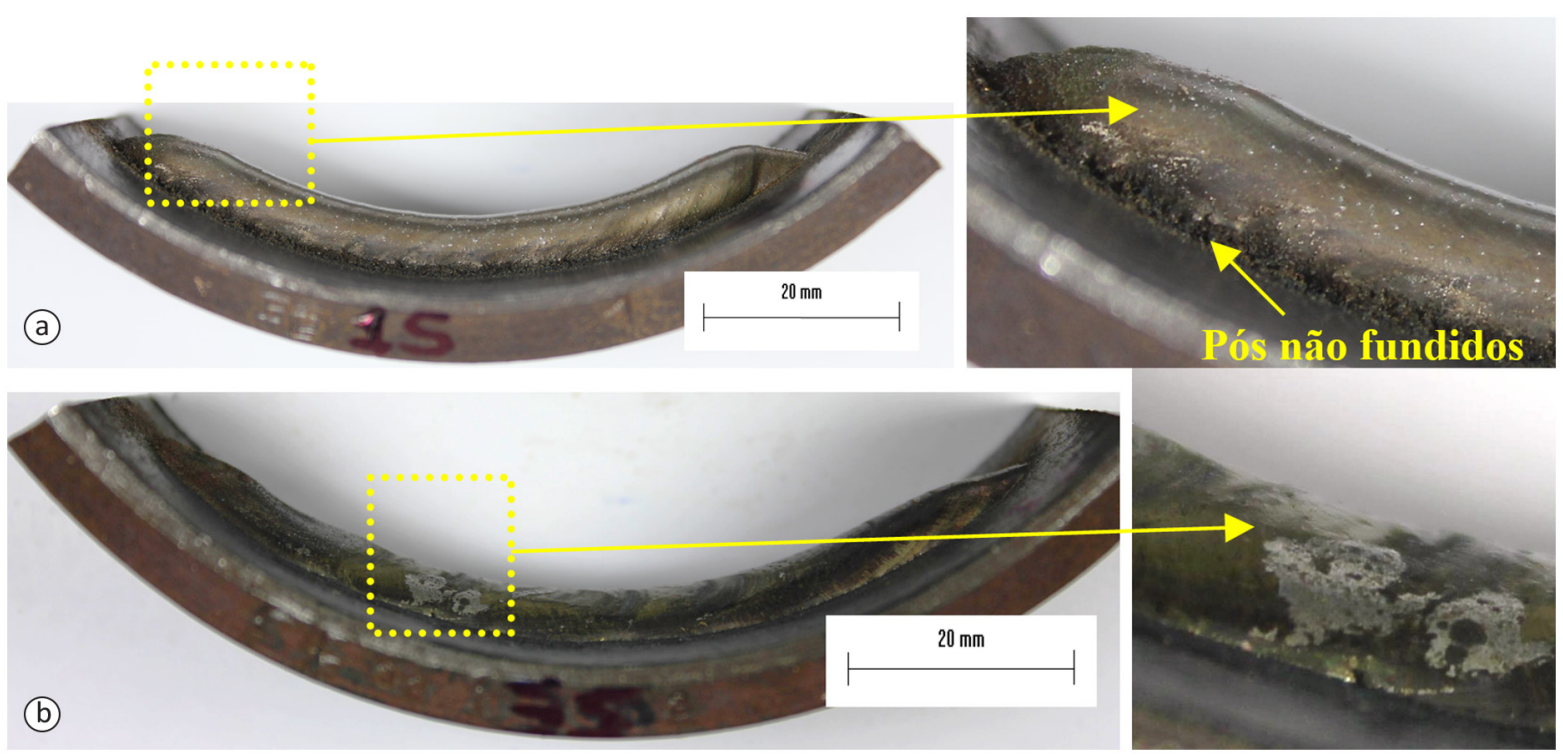

Figura 6. Aspecto superficial do cordão. (a) Condição 1 (E = 11,7 kJ/cm, I = 75 A e Vs = 9 cm/min); (b) condição 3 $(\mathrm{E}=23,5 \mathrm{~kJ} / \mathrm{cm}, \mathrm{I}=150 \mathrm{~A}$ e $\mathrm{Vs}=9 \mathrm{~cm} / \mathrm{min})$.

Dentre as alternativas para minimizar a quantidade de pó não fundido tem-se a redução da taxa de alimentação do pó ou variação da Distância Bico-Peça (DBP) que pode modificar a distância entre o local de incidência do pó e a poça, de modo que as partículas podem passar mais tempo ao longo do arco até alcançar a poça de fusão. Além disso, o aumento da DBP acarreta no aumento da potência do arco, ocasionando maior capacidade de fusão do pó. Outro aspecto é a redução da vazão de gás de arraste que pode proporcionar menor quantidade de pós não fundidos, melhorando a qualidade do cordão de solda. 
A maior quantidade de partículas não fundidas independe da boa ligação com o substrato, e pode estar relacionada com a intensidade de corrente utilizada ser suficiente ou não para garantir a fusão completa de todo o pó [24]. Nestas condições de soldagem, o refinamento dos parâmetros de processamento como um todo deverá ser o alvo do usuário do processo. Na maioria das condições de soldagem foi observada a presença de falta de fusão e porosidades nos cordões de solda, com exceção da condição 3 ( $E=23,5 \mathrm{~kJ} / \mathrm{cm}, \mathrm{I}=150 \mathrm{~A}$ e Vs $=9 \mathrm{~cm} / \mathrm{min}$ ), proveniente da maior corrente de soldagem utilizada. Na condição de mais baixa energia, com menor nível de corrente foi observada falta de fusão nas laterais do cordão e ao longo da linha de fusão.

Na Figura 7 são mostrados alguns defeitos existentes, principalmente nas condições de mais baixa energia, com presença de falta de fusão e poros no metal de solda. Díaz [25] verificou em seu trabalho que velocidades mais altas proporcionaram falta de fusão nas laterais do revestimento, o mesmo observado neste trabalho.

A Figura 8 mostra as seções transversais das amostras soldadas para os diversos níveis de energia (variação ela corrente ou velocidade de soldagem). São verificadas condições bem distintas nas características geométricas dos cordões depositados, principalmente quando ocorre alteração da corrente de soldagem.

Na Figura 9 são mostrados os gráficos da influência da variação da energia de soldagem no reforço e na largura do cordão de solda nas 4 condições de soldagem.

O aumento da energia de soldagem pela variação da corrente de soldagem (Tipo I) proporcionou redução do reforço, principalmente da energia intermediária para a mais elevada. As dimensões dos cordões estão relacionadas através da sua convexidade, principalmente quando se fala de reforço, sendo este inversamente proporcional a intensidade de corrente utilizada. Por outro lado, o aumento da energia de soldagem pela redução da velocidade de soldagem (Tipo V) proporcionou aumento do reforço. A corrente de soldagem em relação à velocidade de soldagem foi o fator que teve mais influência significativa no reforço.
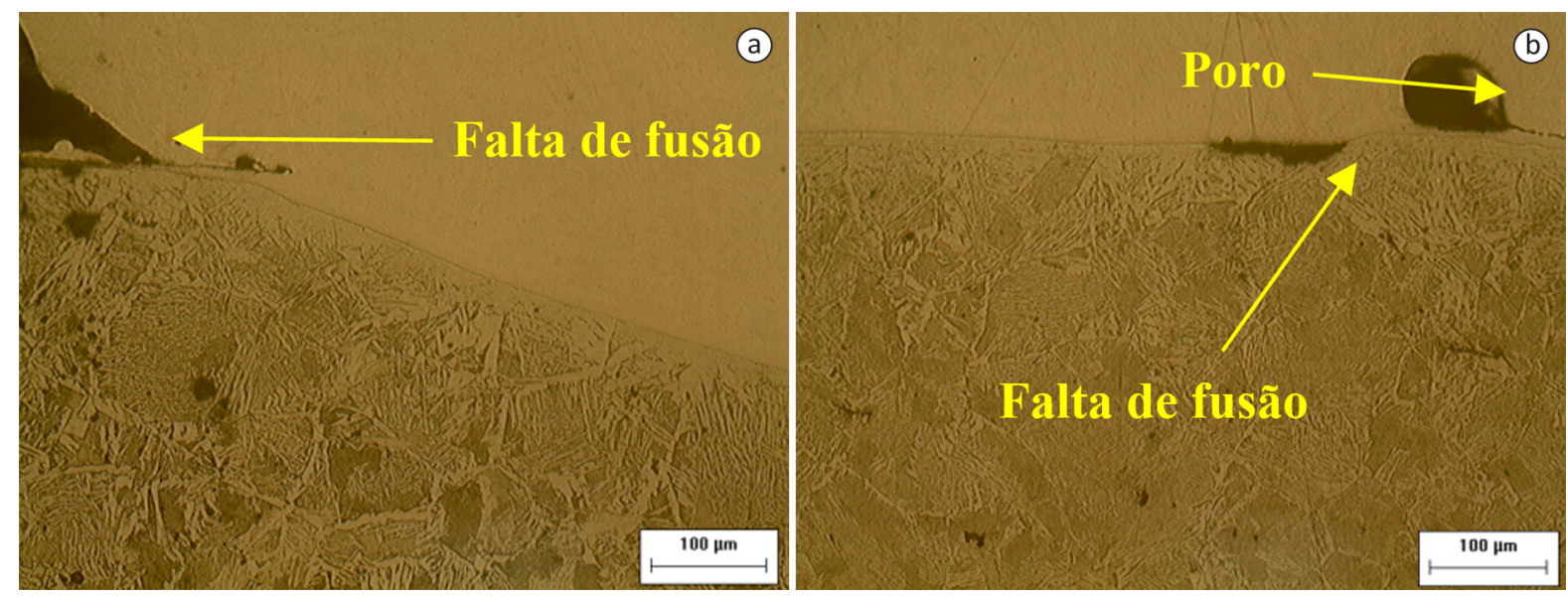

Figura 7. Defeitos na interface dos cordões de solda. (a) Condição 2 ( $E=15,6 \mathrm{~kJ} / \mathrm{cm}, \mathrm{I}=100 \mathrm{~A}$ e Vs $=9 \mathrm{~cm} / \mathrm{min}$ ); (b) Condição 5 ( $E=11,7 \mathrm{~kJ} / \mathrm{cm}, \mathrm{I}=100 \mathrm{~A}$ e Vs $=12 \mathrm{~cm} / \mathrm{min})$.

\begin{tabular}{|c|c|c|c|c|}
\hline $\mathbf{1}$ & $\mathbf{2}$ & $\mathbf{3}$ & $\mathbf{4}$ & $\mathbf{5}$ \\
\hline & & & & \\
& & & & \\
\hline & & & & \\
\hline $\mathrm{I}=75 \mathrm{~A}$ & $\mathrm{I}=100 \mathrm{~A}$ & $\mathrm{I}=150 \mathrm{~A}$ & $\mathrm{I}=100 \mathrm{~A}$ & $\mathrm{I}=100 \mathrm{~A}$ \\
\hline $\mathrm{Vs}=9 \mathrm{~cm} / \mathrm{min}$ & $\mathrm{Vs}=9 \mathrm{~cm} / \mathrm{min}$ & $\mathrm{Vs}=9 \mathrm{~cm} / \mathrm{min}$ & $\mathrm{Vs}=6 \mathrm{~cm} / \mathrm{min}$ & $\mathrm{Vs}=12 \mathrm{~cm} / \mathrm{min}$ \\
\hline $\mathrm{E}=11,7 \mathrm{~kJ} / \mathrm{cm}$ & $\mathrm{E}=15,6 \mathrm{~kJ} / \mathrm{cm}$ & $\mathrm{E}=23,5 \mathrm{~kJ} / \mathrm{cm}$ & $\mathrm{E}=23,5 \mathrm{~kJ} / \mathrm{cm}$ & $\mathrm{E}=11,7 \mathrm{~kJ} / \mathrm{cm}$ \\
\hline
\end{tabular}

Figura 8. Macrografia das amostras soldadas. 
Avaliação do Efeito da Energia de Soldagem na Deposição de Aço Inoxidável Superduplex pelo Processo Plasma Pó
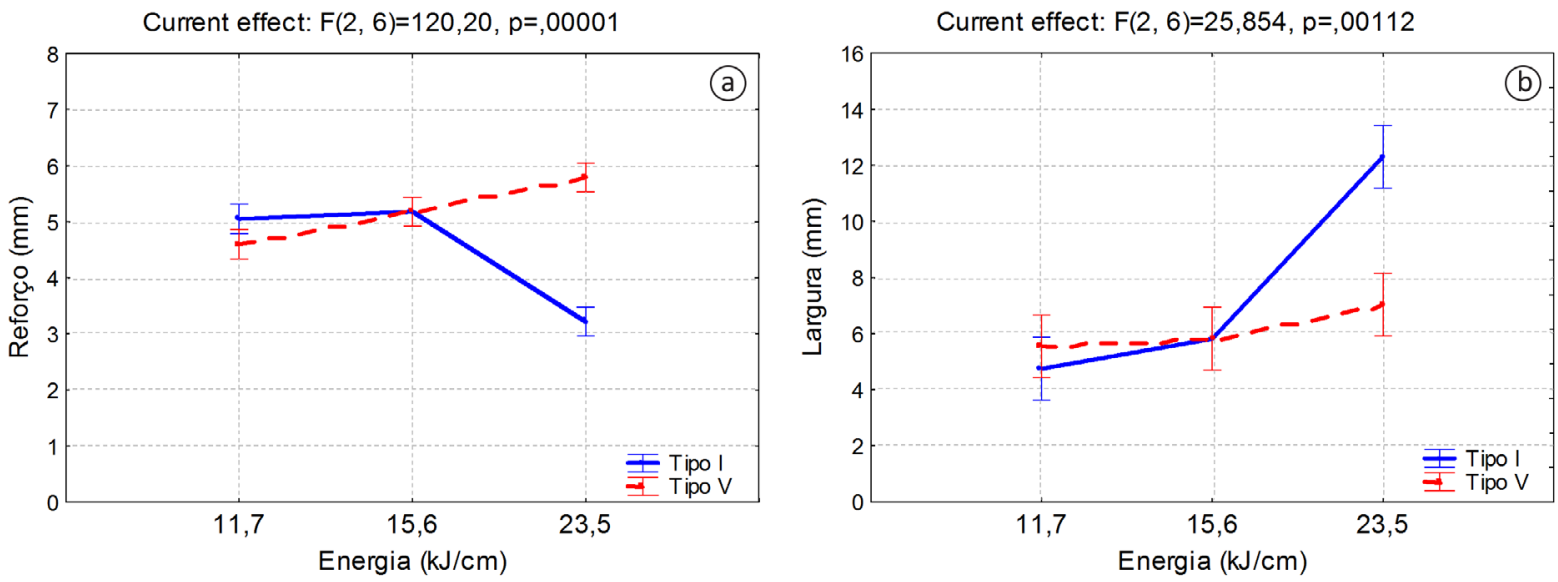

Figura 9. Influência da energia de soldagem. (a) reforço; (b) largura.

Graf [9] verificou que o aumento da corrente de soldagem proporcionou aumento da largura do cordão de solda, redução do reforço e maior nível de diluição. Santos et al. [24] verificaram que o reforço é inversamente proporcional a intensidade de corrente utilizada. A maior quantidade de calor diminui a viscosidade do metal líquido, tornando a poça mais fluida, aumentando a molhabilidade e, consequentemente, reduzindo o reforço, devido ao aumento da temperatura e diâmetro do arco e maior pressão do arco plasma. As forças eletromagnéticas e as forças cisalhantes oriundas do jato de plasma também aumentam com o acréscimo de corrente, de modo que atuam no mecanismo de convecção do metal líquido da poça, principalmente a força de cisalhamento que provoca escoamento do gás de plasma sobre a superfície da poça, que pode ocasionar o arraste do líquido do topo da poça para a borda, reduzindo o reforço [26].

O aumento da velocidade de soldagem resulta em menores tempos para a deposição do pó, ocorrendo deposição de cordões com menor reforço. Estes resultados mostram que a variação da energia pode acarretar em características distintas, lodo deve-se verificar que alteração é satisfatória para determinada condição, variação da corrente ou velocidade de soldagem. Díaz [25] também verificou que a medida que a velocidade de soldagem aumenta com redução da energia de soldagem, o reforço diminui. Na aplicação de revestimentos internos de aços inoxidáveis, tanto para chapas cladeadas, quanto para tiras soldadas (lining) e deposição de soldas (weld overlay), é recomendada uma espessura mínima de $3 \mathrm{~mm}$ para revestimentos [26]. Neste trabalho, as soldagens realizadas com a mesma energia $(23,5 \mathrm{~kJ} / \mathrm{cm})$ podem acarretar em comportamentos distintos em relação à geometria, de modo que a condição soldada com corrente de $150 \mathrm{~A}$ e velocidade de $9 \mathrm{~cm} / \mathrm{min}$ proporcionou reforço de 3,2 $\mathrm{mm}$. Por outro lado, a condição soldada com corrente de 100 A e velocidade de $6 \mathrm{~cm} / \mathrm{min}$ acarretou em reforço de $5,8 \mathrm{~mm}$. Os cordões apresentaram níveis superiores a $3 \mathrm{~mm}$ de reforço, sendo o recomendado para um posterior revestimento com deposição de apenas uma camada.

Em relação à largura, é importante que seja obtido níveis maiores de largura para ocorrer maior produtividade e redução de custos. O aumento da energia de soldagem proporcionou maior largura dos cordões de solda, de modo que a corrente de soldagem foi o parâmetro que influenciou de forma mais significativa. Ocorre acréscimo no aporte térmico (relação entre potência e velocidade de soldagem) fornecido para a formação da poça de fusão devido o aumento da corrente de soldagem. Nos ensaios realizados foram observadas grandes variações de largura, sendo que para corrente de 75 A foi obtida uma largura de 4,7 mm em média e para a condição soldada com $150 \mathrm{~A}$, a largura obtida foi de $12,3 \mathrm{~mm}$.

Díaz [25] verificou que a largura do depósito aumenta levemente com a corrente de soldagem e a largura diminui com o aumento da velocidade de soldagem devido à menor quantidade de material depositado por unidade linear do cordão. Takeyama [27] verificou que para mesma taxa de deposição, os cordões depositados com 170 A resultaram em cordões mais largos e de altura de reforço menor comparados aos depositados com correntes de $150 \mathrm{~A}$. 
Na Figura 10 são mostrados os gráficos da influência da alteração da energia em relação à diluição e ao ângulo de molhamento.
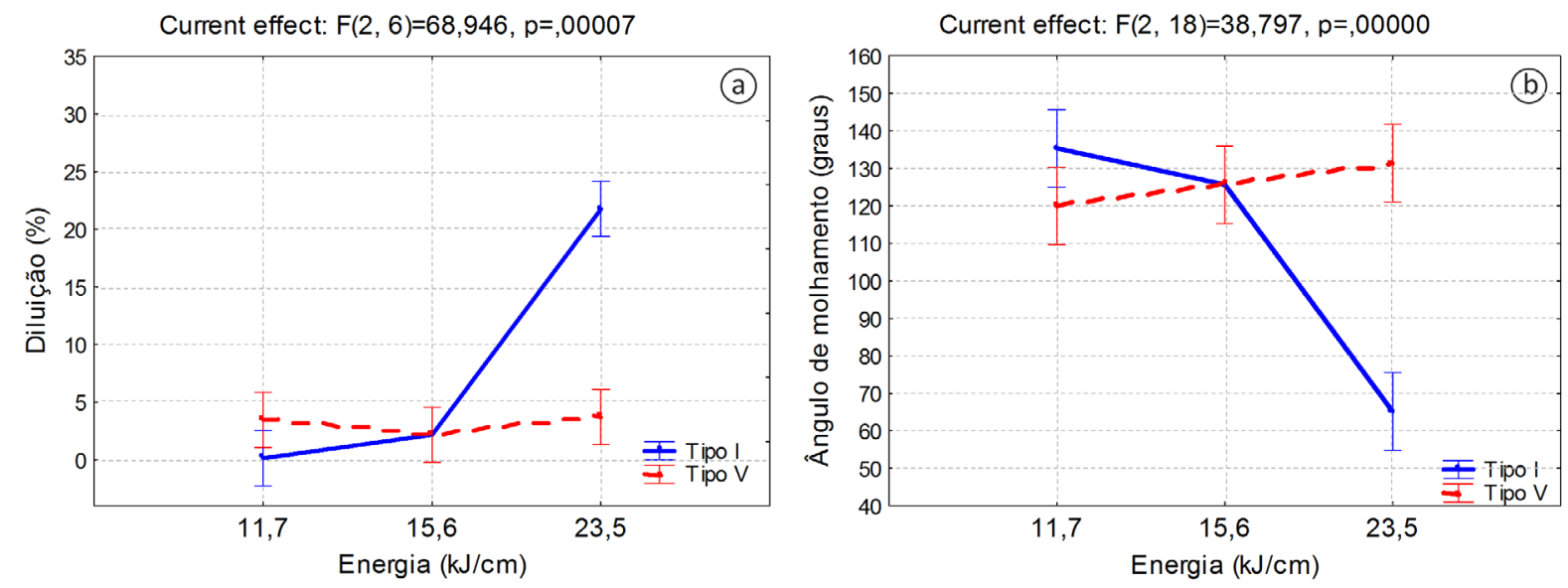

Figura 10. Influência da energia de soldagem. (a) diluição; (b) ângulo de molhamento.

Em relação à diluição foi verificado que a variação da energia de soldagem pela alteração da velocidade de soldagem não ocasionou influência significativa em termos estatísticos, ou seja, pode-se alterar a energia sem comprometer o nível de diluição. Porém, a variação da energia de soldagem pela alteração da corrente de soldagem proporcionou alteração na diluição de forma bem significativa, sendo que o aumento da energia de soldagem acarretou no acréscimo dos níveis de diluição.

Os fenômenos envolvidos para o aumento da diluição com o aumento da corrente de soldagem são os mesmos descritos para o aumento da penetração. O aumento da pressão do arco plasma e atuação das forças eletromagnéticas contribuem para o movimento convectivo no metal líquido na poça de fusão, de modo que este ocorre na região mais quente da poça (centro da superfície) para o fundo da mesma, aumentando desta forma a diluição [28].

O aumento da energia pela alteração da corrente de soldagem ocasionou redução do reforço, de modo que ocasiona a redução da barreira entre o calor do arco e o substrato. A barreira sendo menos efetiva, o calor destinado ao substrato é maior, ocasionando maior diluição.

Quanto maior o nível de corrente, o calor gerado é maior e o excesso de calor é disponibilizado para fundir o substrato depois da fusão do pó. A geração da maior quantidade de calor aumenta a força do arco e subsequentemente aumenta a penetração no material do substrato [29]. Esta maior penetração conduz para um maior percentual de diluição quando a corrente do arco transferido aumenta. Para níveis de corrente mais baixos, a geração de calor é menor e a maior parte do calor é utilizado para fundir o pó e a menor parcela é disponibilizado para fundir o substrato depois da fusão do pó. Além disso, a força do arco é menor para esta condição, proporcionando uma redução da profundidade.

O efeito da variação da energia pela alteração da velocidade de soldagem não é tão eficaz, pois ao mesmo tempo em que uma velocidade de soldagem baixa acarreta em maior tempo de soldagem em determinado ponto, há mais material depositado, servindo como barreira entre substrato e o arco plasma. que a velocidade de soldagem tem sua maior influência na forma como o calor se distribui na poça de fusão [30].

Neste grupo de soldagem foi observado um pequeno aumento da diluição para energia de $11,7 \mathrm{~kJ} / \mathrm{cm}$ em relação à energia de 15,6 kJ/cm, apesar de não ser relevante e significante, devido possivelmente à maior velocidade de soldagem empregada $(12 \mathrm{~cm} / \mathrm{min}$ ) que acarreta menor material depositado por unidade de linear de comprimento, diminuindo desta forma a barreira entre arco e substrato, aumentando a diluição. Este comportamento também foi observado por Kannan e Murugan [13] que observou que para elevadas velocidades de soldagem na 
Avaliação do Efeito da Energia de Soldagem na Deposição de Aço Inoxidável Superduplex pelo Processo Plasma Pó

deposição de aço inoxidável duplex com arame tubular proporcionou aumento da diluição. No entanto, para o nível mais elevado de energia foi observado um pequeno aumento da diluição, sendo que neste caso a aplicação de velocidade de soldagem mais baixa ocasiona maior tempo do arco sobre o substrato, de modo que ocasionar maior diluição. Porém, é observado que a variação da velocidade não acarretou em grandes diferenças na diluição, possivelmente devido a esses dois fatores que possuem efeitos opostos.

Para um revestimento satisfatório em termos de preservação das características do metal de solda não são recomendados valores de diluição superiores a 20\% [31]. Níveis elevados de diluição acarretam aumento de carbono e redução de níquel e cromo no metal de solda próximo à interface, de modo a se afastar da composição química do metal de adição, reduzindo as propriedades benéficas no metal de adição. De modo geral, foram obtidos níveis baixos de diluição, sendo um resultado de bastante importância para uma posterior soldagem de revestimentos. Srimath e Murugan [32] realizando deposição de aço inoxidável SS410L (Cr-Si-Ni) em aço carbono ASTM A105, verificaram que o aumento da corrente de soldagem (80 até 112 A) proporcionou aumento da diluição e largura, porém com redução do reforço.

A molhabilidade dos cordões pode ser avaliada qualitativamente através do ângulo de molhabilidade ou de contato $(\theta)$ formado entre e superfície sólida e o plano tangencial à superfície do cordão depositado. Se $\theta<90^{\circ}, 0$ líquido tem tendência a molhar a superfície e o oposto ocorre para $\theta>90^{\circ}$. Portanto, quanto menor este ângulo, melhor será o molhamento. Este ângulo tem a importância para a prevenção de defeitos de soldagem multipasse, sendo que a convexidade causa porosidade e falta de fusão [24]. Foi verificado que o aumento da energia pela variação da corrente de soldagem acarretou na redução do ângulo de molhamento, deixando a poça de fusão mais fluida, facilitando o escoamento. No entanto, o aumento da energia de soldagem com a variação da velocidade acarretou, de forma geral, aumento do ângulo de molhamento. A maioria dos cordões obteve desempenho ruim em relação à molhabilidade devido a maior tensão superficial, menor fluidez e elevada taxa de alimentação de pó. Esta característica resposta foi a mais difícil em relação à obtenção de resultados satisfatórios, logo sugere-se uma possível alteração da taxa de alimentação de pó para níveis mais baixos, sendo este controle realizado de forma independente, sendo uma característica peculiar deste processo.

Fica notório que a variação da energia, via alteração da corrente ou velocidade de soldagem, acarreta em comportamentos distintos em relação às características geométricas, sendo uma informação importante para aplicações industriais do processo Plasma Pó.

Na Figura 11 é verificada a influência da energia de soldagem no teor de ferrita do metal de solda do AISD.

Foi verificado maior influência da corrente de soldagem no percentual de ferrita no metal de solda, de modo que o aumento da energia de soldagem pela alteração da corrente de soldagem proporcionou redução do teor de ferrita. Um aumento da corrente de soldagem proporciona uma menor velocidade de resfriamento, sendo que desta maneira há um maior tempo para a austenita nuclear e crescer. Por outro lado, o efeito da velocidade de soldagem não foi tão significante, ocorrendo redução pequena do percentual de ferrita.

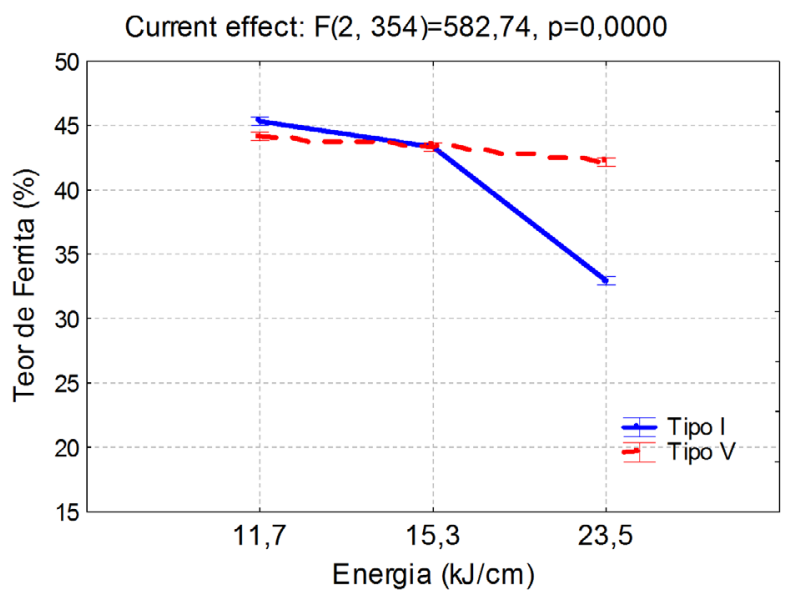

Figura 11. Influência da energia de soldagem no teor de ferrita do metal de solda. 
Segundo a literatura a faixa recomendada do teor de ferrita no metal de solda varia de acordo com o processo de soldagem, aplicação, dentre outros fatores [33,34]. Segundo a norma NORSOK M-601, o teor de ferrita deve estar na faixa de 30 a 70\% [35], de modo que teores baixos de ferrita podem acarretar redução da resistência à fissuração por corrosão sob tensão e valores elevados de ferrita proporcionam perca da boa ductilidade e tenacidade. Este grupo de condições apresentaram quatro condições com valores próximos de $45 \%$ de ferrita no metal de solda. É importante verificar que se pode alterar a energia de soldagem sem trazer grandes alterações no teor de ferrita, quando ocorre alteração da velocidade de soldagem. Vale salientar que na soldagem de revestimento a situação é mais crítica, devido à soldagem multipasse, provocando aquecimentos e reaquecimento que acarretam na redução do teor de ferrita.

Na Figura 12 são mostrados os gráficos da influência da energia de soldagem nos níveis de microdureza para todas as condições soldadas. As linhas verticais representam a região da linha de fusão e a distância na abscissa representa o deslocamento das medidas a partir da primeira impressão realizada no topo do metal de solda.
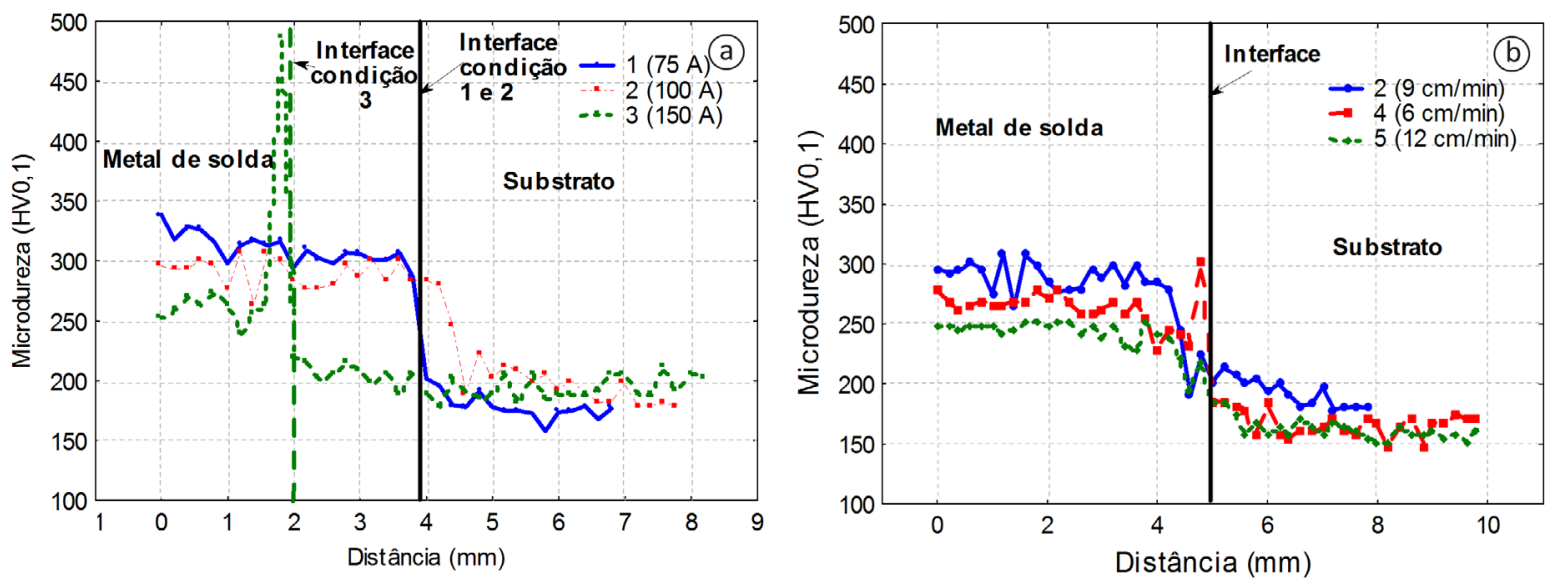

Figura 12. Perfis de microdureza. (a) alteração da corrente de soldagem; (b) alteração da velocidade de soldagem.

Foram observados maiores níveis de microdureza no metal de solda em relação ao metal base, sendo que quando ocorreu variação da energia pela alteração da corrente de soldagem, as condições de menor energia apresentaram maiores níveis de microdureza, por possivelmente apresentarem maior teor de ferrita no metal de solda, pois esta fase acarreta em maior microdureza no metal de solda, sendo que a fase austenítica é mais macia e tenaz [36]. A condição soldada com maior nível de corrente apresentou um elevado pico de microdureza, próximo de $500 \mathrm{HV}$, e menores níveis de microdureza ao longo do metal de solda, devido à maior nível de diluição e possivelmente, empobrecimento de elementos de liga no metal de solda, como: nitrogênio (alta difusividade), cromo, molibdênio e níquel. Na soldagem de revestimento, a interface é a região mais crítica, pois devido à diluição, a composição química do metal de solda perto da interface é diferente, ocorrendo uma certa heterogeneidade, sendo importante não ocorrer redução das propriedades mecânicas e resistência à corrosão. Possivelmente, a difusão de carbono do metal base para o metal de solda pode ter ocasionado regiões de elevada dureza próximo à interface (Figura 12a, condição 3) como já relatado na literatura [37].

Na variação da energia pela alteração da velocidade de soldagem, foi observado um pico de microdureza na condição de maior nível de energia próximo à interface, porém com nível relativamente baixo, aproximadamente 300 HV. Na Figura 13 são mostradas algumas impressões de microdureza, evidenciando a região de elevada microdureza próximo à interface, sendo uma região crítica, podendo ocasionar defeitos, como trincas, principalmente em condições severas de serviço. Vale salientar que para este material é recomendado um valor máximo de 330 HV10, de modo que o nível mais baixo e mais elevado de corrente não foi satisfatório para fins de aplicação [38]. 


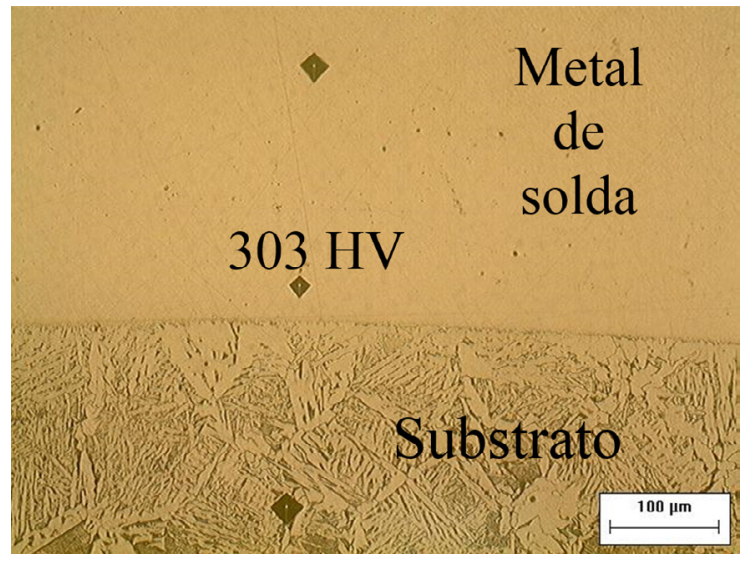

Figura 13. Impressões de microdureza próximas à interface (Condição 4).

Dentre as condições estudadas, a que apresentou melhores resultados em relação à característica geométrica, teor de ferrita e microdureza foi a condição $5(E=11,7 \mathrm{~kJ} / \mathrm{cm}, \mathrm{I}=100 \mathrm{~A}$ e Vs $=12 \mathrm{~cm} / \mathrm{min})$, porém deve ser feito ainda um melhor ajuste de outros parâmetros para principalmente diminuir o ângulo de molhamento. A condição 5 obteve reforço de 4,6 mm, largura de 5,4 mm, diluição de 3,4\%, ângulo de molhamento de 125,60, teor de ferrita de $44,2 \%$ e microdureza média do metal de solda de 245 HV0,1.

\section{4 . Conclusões}

Com base nos resultados obtidos e apresentados no trabalho, foi possível concluir que:

- As condições soldadas com nível mais elevado de corrente proporcionou um melhor acabamento superficial e redução de defeitos, como poros e falta de fusão;

- O aumento da energia pela alteração da corrente de soldagem proporcionou alteração das características geométricas de forma mais significativa com aumento da largura e diluição e redução do reforço, ângulo de molhamento e teor de ferrita no metal de solda;

- A condição soldada com maior nível de corrente (150 A) proporcionou menores níveis de microdureza global do metal de solda;

- Os resultados mostraram ser promissores, porém deve haver maior exploração de outros parâmetros para obter revestimento de boa qualidade em relação principalmente à molhabilidade do cordão de solda.

\section{Agradecimentos}

Os autores agradecem ao Laboratório de Engenharia de Soldagem pelo apoio laboratorial e aos órgãos de fomento: CAPES, FINEP, Prh-31 pela concessão da bolsa e apoio financeiro.

\section{Referências}

[1] Petrobras. Plano de Negócios 2009-2013. Brasília: Petrobras; 2009.

[2] Brown A. Weld overlay cladding - the solution to pump corrosion? World Pumps. 2005;2005(469):50-53. http://dx.doi. org/10.1016/S0262-1762(05)70785-9.

[3] Wang $\mathrm{H}$, Jiang WH, Valant M, Kovacevic R. Micro-plasma powder deposition as a new solid freeform fabrication process. Journal of Engineering Manufcaturing. 2003;217(12):301-312.

[4] Lakshminarayanan AK, Balasubramanian V, Varahamoorthy $\mathrm{R}$, Babu S. Predicting the dilution of plasma transferred arc hardfacing of stellite on carbon steel using response surface methodology. Metals and Materials International. 2008;14(6):779789. http://dx.doi.org/10.3365/met.mat.2008.12.779.

[5] Liyanage T, Fisher G, Gerlich AP. Influence of alloy chemistry on microstructure and properties in NiCrBSi overlay coatings deposited by plasma transferred arc welding (PTAW). Surface and Coatings Technology. 2010;205(3):759-765. http://dx.doi. org/10.1016/j.surfcoat.2010.07.095.

[6] Nelson TW, Lippold JC, Mills MJ. Investigation of boundaries and structures in dissimilar metals welds. Science and Technology 
of Welding and Joining. 1998;3(5):249-255. http://dx.doi. org/10.1179/stw.1998.3.5.249.

[7] D'Oliveira ASCM, Paredes RSC, Santos RLC. Pulsed current plasma transferred arc hardfacing. Journal of Materials Processing Technology. 2006;171(2):167-174. http://dx.doi.org/10.1016/j. jmatprotec.2005.02.269.

[8] Graf K, D'Oliveira ASCM. Microstructural Stability and Wear Performance of a Ni Based Alloy PTA Coating. In: Proceedings of the 17th International Congress of Mechanical Engineering COBEM; 2003 Nov. 10-14; São Paulo; São Paulo: COBEM;.2003. p. 156-161.

[9] Graf K. Estabilidade a alta temperatura de revestimentos de hastelloy c depositados por PTA [dissertação de mestrado]. Curitiba: Universidade Federal do Paraná; 2004.

[10] Ramírez AJ. Estudo da precipitação de nitreto de cromo e fase sigma por simulação térmica da zona afetada pelo calor na soldagem multipasse de aços inoxidáveis duplex [dissertação de mestrado]. São Paulo: Departamento de Eng. Metalúrgica da Escola Politécnica da USP; 1997.

[11] Ramírez AJ. Precipitação de fases intermetálicas e austenita secundária na ZAC de soldagens multipasse de aços inoxidáveis duplex [tese de doutorado]. São Paulo: Universidade de São Paulo; 2001.

[12] Notten G. Application of duplex stainless steel in the chemical process industry. In: Duplex Stainless Steel. 5th World Conference; 1997 October 21-23; Maastricht, Netherlands. Maastricht: KCl Publish; 1997. p. 9-16.

[13] Kannan T, Murugan N. Prediction of ferrite number of duplex stainless steel clad metals using RSM. Welding Journal. 2006(Supl):91-100.

[14] Barnhouse J, Lippold JC. Microstructure/property relationships in dissimilar welds between duplex stainless steels and carbon steels. American Welding Society. 1998;77(12):477-487.

[15] Scott P. Sunrise LNG development - review of mechanical and corrosion testing of CRA flowlines. Perth: Woodside; 2010.

[16] Rajeev R, Samajdar I, Raman R, Harendranatha CS, Kale GB. Origin of hard and soft zone formation during cladding of austenitic/duplex stainless steel on plain carbon steel. Materials Science and Technology. 2001;17(8):1005-1011. http://dx.doi. org/10.1179/026708301101510852.

[17] Ogata PH, Ramírez MG, Goldenstein H, Gorni AA, Landgraf FJG. Caracterização microestrutural de aço API 5LX65, austenitizado e resfriado a diferentes taxas de resfriamento. $\ln : 18^{\circ}$ Congresso Brasileiro de Engenharia e Ciência de Materiais - CBECiMat; 2008 Nov. 24-28; Porto de Galinhas, Brasil; Porto de Galinhas: Universidade Estadual de Maringá; 2008. p. 106-116.

[18] Ogata PH. Caracterização microestrutural do aço para tubo API 5L-X65 em diferentes regiões da chapa como laminada e após austenização e resfriamento sob diversas taxas de resfriamento [dissertação de mestrado]. São Paulo: Universidade de São Paulo; 2009.

[19] Rancis R., Warburton G. Marine corrosion resistance of ZERON 100 superduplex stainless steel. Tulsa: Rolled Alloys; 2008. Report \#TN779.

[20] Oliveira MA. Estudo do processo plasma com alimentação automática de arame [dissertação de mestrado] Florianópolis: Universidade Federal de Santa Catarina; 2001.

[21] Deuis RL, Yellup JM, Subramanian C. Metal-matrix composite coatings by PTA surfacing. Composites Science and Technology. 1998;58(2):299-309. http://dx.doi.org/10.1016/S02663538(97)00131-0.

[22] Ribeiro HO. Desenvolvimento de ligas para revestimentos por PTA resistentes à cavitação [tese de doutorado]. Florianópolis: Universidade Federal de Santa Catarina; 2007.
[23] Balasubramanian V, LAKSHMINARAYANAN AK, VARAHAMOORTHY $\mathrm{R}, \mathrm{BABU} \mathrm{S}$. Application of response surface methodolody to prediction of dilution in plasma transferred arc hardfacing of stainless steel on carbon steel. Journal of Iron and Steel Research International. 2009;16(1):44-53. http://dx.doi.org/10.1016/ S1006-706X(09)60009-1.

[24] Santos RLC. Deposição por plasma de arco transferido com corrente contínua pulsada [dissertação de mestrado]. Curitiba: Universidade Federal do Paraná; 2003.

[25] Díaz VMV. Inovação do equipamento e avaliação do processo plasma de arco transferido alimentado com pó (PTAP) para soldagem fora de posição [tese de doutorado]. Florianópolis: Universidade Federal de Santa Catarina; 2005.

[26] Fan HG, Shi YW. Numerical simulation of the arc pressure in gas tungsten arc welding. Journal of Materials Processing Technology. 1996;61(3):302-308. http://dx.doi.org/10.1016/09240136(95)02190-6.

[27] Takeyama RR. Caracterização de revestimentos de ligas à base de co modificadas pela adição de carbonetos de tungstênio [dissertação de mestrado]. Curitiba: Universidade Federal do Paraná; 2005.

[28] Kou S, Sun DK. Fluid flow and weld penetration in stationary arc welds. Metallurgical Transactions. A, Physical Metallurgy and Materials Science. 1985;16(2):203-213. http://dx.doi. org/10.1007/BF02816047.

[29] Bharath RR, Ramanathan R, Sundararajan B, Srinivasan PB. Optimization of process parameters for deposition of stellite on $\mathrm{X} 45 \mathrm{CrSi93}$ steel by plasma transferred arc technique. Materials \& Design. 2008;29(9):1725-1731. http://dx.doi.org/10.1016/j. matdes.2008.03.020.

[30] Kuwabara EY, Graf K, D'Oliveira ASCM. Revestimento de Níquel Reforçados com WC Depositados por Plasma com Arco Transferido. In: 20 Congresso Brasileiro de Engenharia de Fabricação - COBEF; 2003 May 18-21; Uberlândia, Brasil. Uberlândia: ABCM; 2003.

[31] Triguinho JJ. Superfícies enriquecidas por carbonetos de tungstênio depositados a plasma por arco transferido [dissertação de mestrado]. Curitiba: Universidade Federal do Paraná; 2005.

[32] Srimath N, Murugan N. Prediction and Optimisation of weld bead geometry of plasma transferred arc hardfaced valve seat rings. European Journal of Scientific Research. 2011;51(: 2):285-298.

[33] Taban E. Toughness and microstructural analysis of superduplex stainless steel joined by plasma arc welding. Journal of Materials Science. 2008;43(12):4309-4315. http://dx.doi.org/10.1007/ s10853-008-2632-z.

[34] Tavares SSM, Castro JLG, Côrte RRA, Souza VM, Pardal JM. Detecção de pequenos teores de fase sigma e avaliação dos seus efeitos na resistência à corrosão do aço inoxidável duplex UNS S31803. ENGEVISTA. 2006;8(2):77-82.

[35] Standards Norway. Norsok Standard M-601: welding and Inspection of piping. 5. ed. Lysaker: Standards Norway; 2008.

[36] Young MC, Chan SLI, Tsay LW, Shin CS. Hydrogen-enhanced cracking of 2205 duplex stainless steel welds. Materials Chemistry and Physics. 2005;91(1):21-27. http://dx.doi.org/10.1016/j. matchemphys.2004.10.042.

[37] Srinivasan PB, Muthupandi V, Dietzel W, Sivan V. Microstructure and corrosion behavior of shielded metal arc-welded dissimilar joints comprising duplex stainless steel and low alloy steel. Journal of Materials Engineering and Performance. 2006;15(6):758-764. http://dx.doi.org/10.1361/105994906X150902.

[38] Standards Norway. Norsok Standard M-630: material data sheets for piping. Lysaker: Standards Norway; 1997. 